\title{
Lecciones y estrategias para lograr una Maestría
}

GREENE, ROBERT (2012). Maestría. México, D.F.: Océano. 376 pp.

Durante el transcurso de nuestra vida, inevitablemente debemos enfrentar diversos factores para lograr nuestros objetivos. Independientemente de que seamos diferentes, de que tengamos diversas convicciones, intereses y metas por alcanzar, existe en el individuo una fuerza interior mucho más poderosa, esa fuerza le permite salir adelante y cumplir sus propósitos. Para alcanzar nuestros objetivos hay que recorrer un camino muy largo, es un proceso lento, pero si elegimos el camino correcto es seguro que lo lograremos. He ahí la importancia de disciplinarnos a nosotros mismos, de vencer nuestros miedos y dejar que afloren nuestras ideas para dar un paso más allá y alcanzar la maestría.

El proceso de alcanzar la maestría es lo que Greene trata de explicar en su libro. Proporciona un cúmulo de consejos para motivarnos a seguir adelante por el sendero de la vida como verdaderos guerreros, ansiosos por romper los obstáculos que entorpecen nuestro camino. Nos invita a ser fuertes y constantes con el oficio que hayamos elegido, porque es la única manera en que podremos salir adelante.

Para Greene (2012) la maestría es "la impresión de que tenemos un mayor dominio de la realidad, los demás y nosotros mismos", alcanzarla no es un camino fácil ni se llega a ella por arte de magia: es un proceso difícil. Se deben superar tres etapas: la primera es el aprendizaje del oficio; la segunda es la fase creativa-activa; y la tercera es la maestría. Afirma que tras estas etapas seremos personas con un mayor conocimiento y capacidad para entender nuestra realidad. Es entonces cuando podremos conocer las reglas del juego e incluso romperlas o imponer las propias. 
El texto está dirigido a todos aquellos profesionales convencidos y dispuestos a realizar sus proyectos de vida, con la firme convicción de que las cosas pueden hacerse y ser diferentes si se rompen las barreras y obstáculos que se presentan en el camino. El autor lleva al lector de la mano por el texto y comparte diversas estrategias para adquirir conocimiento al más alto nivel, para lograr el cambio y alcanzar la maestría.

El libro está organizado en seis capítulos en los que expone investigaciones de las ciencias neurológicas y cognitivas, así como estudios sobre creatividad. Para un mejor entendimiento ofrece profundos pensamientos de célebres personalidades, así como biografías de grandes maestros de la historia, describiendo sus perfiles como ejemplos clave para motivar y mostrar cómo ellos supieron manejar obstáculos en su vida, y su condición social o económica no impidió que se convirtieran en grandes maestros. Además en cada capítulo indica las lecciones aprendidas, el proceso y las estrategias que se pueden implementar en la resolución de problemas para alcanzar la maestría.

"Descubre tu llamado: tu tarea en la vida", es el punto de partida; debemos establecer nuestra identidad, que nos guiará a paso firme por el camino elegido, sin permitir que nuestra fuerza interior se debilite, ni de dudar aunque las presiones sociales se empeñen en confundirnos. "Ríndete a la realidad: el aprendizaje ideal", "Asimila el poder del maestro: la dinámica del mentor" y "Ve a la gente como es: inteligencia social", son temas que abarcan la fase de aprendizaje, las habilidades para la adquisición de conocimientos, el trabajo con mentores y el cultivo de la inteligencia social, entre otros. "Descubre la mente dimensional: la fase creativa-activa", nos permite entender la relación que existe entre las cosas, una vez que las hemos observado y adquirido práctica. $\mathrm{El}$ sexto capítulo "Funde lo intuitivo con lo racional: maestría" es la meta, la culminación del proceso. El grado de conocimiento adquirido, la experiencia y concentración son profundos y nos permite ver la fotografía completa de las cosas, y el punto central de la investigación: donde habremos alcanzado la maestría buscada.

Este compendio de estrategias y consejos, vertidos en el libro, es bastante útil en cualquier disciplina, sobre todo en la investigación científica. ¿Cuántas veces hemos titubeado al elegir un tema? Quizá no estamos seguros si nos gusta o no, o realmente lo desconocemos. Al respecto, Greene (2012) hace valiosas recomiendaciones: invita a "elegir un tópico que le apasione y enfóquese profundamente en él"; hay que hacer lo que realmente nos guste y comprometernos ciegamente a confiar en nosotros mismos, más que por curiosidad, y a combatir las adversidades con pasión y entrega. También sugiere investigar con plena voluntad y conciencia, "no centrarse en ganar dinero fácil y rápido", una creencia que no funciona y cuya satisfacción es pasajera. Debemos concentrarnos en el oficio elegido y acumular todo el conocimiento que sea posible; cuando hayamos profundizado en el tema, sugiere "seleccionar un mentor" con intereses afines a nuestro proyecto, que guíe de forma cordial y facilite el camino que falta recorrer. Someternos a su autoridad es clave para alcanzar el objetivo trazado. 
Finalmente, "ser flexivo y creativo", es decir, mantenerse siempre con actitud positiva, con la mente abierta y dispuesto a recibir y aceptar críticas y errores, no emitir juicios cuando no hay pleno conocimiento de lo que se dice y ponerse en los zapatos del otro para comprenderlo: lo que Greene llama inteligencia social.

Se concluye que en nuestras manos está la oportunidad de explotar el potencial que tenemos, porque somos nosotros mismos los forjadores de nuestro destino, sin importar clase social o condición económica, porque internamente llevamos la fuente de los mayores logros y descubrimientos. Debemos desarrollar nuestras facultades e inteligencia, solo hay que hacerlo con paciencia, vocación y práctica rigurosa para impulsarnos y convertirnos en verdaderos maestros, sin importar el campo de elegido. La maestría no depende del genio o talento de cada uno: depende del tiempo, la concentración y el esfuerzo aplicados. Hay que aprovechar todo lo que esté a nuestro alcance y poner a trabajar nuestro cerebro, acumulando conocimiento que al paso del tiempo se convertirá en nuestro mayor aliado, nos permitirá abrir los ojos para ver mas allá de lo que otros no ven. Estar siempre con la mente abierta y dispuestos a entender de forma holística nuestra realidad. 